\title{
Enhancement of 1,3-propanediol production from industrial by-product by Lactobacillus reuteri $\mathrm{CH} 53$
}

\author{
Jung-Hyun Ju', ${ }^{1,2+}$, Dexin Wang ${ }^{3,4+}$, Sun-Yeon Heo ${ }^{1}$, Min-Soo Kim', Jeong-Woo Seo ${ }^{1}$, Young-Min Kim², \\ Dae-Hyuk Kim ${ }^{4}$, Soon-Ah Kang ${ }^{5}$, Chul-Ho Kim ${ }^{1 *}$ and Baek-Rock Oh ${ }^{1 *}$ (1)
}

\begin{abstract}
Background: 1,3-propanediol (1,3-PDO) is the most widely studied value-added product that can be produced by feeding glycerol to bacteria, including Lactobacillus sp. However, previous research reported that L. reuteri only produced small amounts and had low productivity of 1,3-PDO. It is urgent to develop procedures that improve the production and productivity of 1,3-PDO.
\end{abstract}

Results: We identified a novel L. reuteri $\mathrm{CH} 53$ isolate that efficiently converted glycerol into 1,3-PDO, and performed batch co-fermentation with glycerol and glucose to evaluate its production of 1,3-PDO and other products. We optimized the fermentation conditions and nitrogen sources to increase the productivity. Fed-batch fermentation using corn steep liquor (CSL) as a replacement for beef extract led to 1,3-PDO production (68.32 $\pm 0.84 \mathrm{~g} / \mathrm{L}$ ) and productivity $(1.27 \pm 0.02 \mathrm{~g} / \mathrm{L} / \mathrm{h})$ at optimized conditions (unaerated and $100 \mathrm{rpm})$. When CSL was used as an alternative nitrogen source, the activity of the vitamin B12-dependent glycerol dehydratase (dhaB) and 1,3-propanediol oxidoreductase (dhaT) increased. Also, the productivity and yield of 1,3-PDO increased as well. These results showed the highest productivity in Lactobacillus species. In addition, hurdle to 1,3-PDO production in this strain were identified via analysis of the half-maximal inhibitory concentration for growth (IC50) of numerous substrates and metabolites.

Conclusions: We used CSL as a low-cost nitrogen source to replace beef extract for 1,3-PDO production in L. reuteri $\mathrm{CH} 53$. These cells efficiently utilized crude glycerol and CSL to produce 1,3-PDO. This strain has great promise for the production of 1,3-PDO because it is generally recognized as safe (GRAS) and non-pathogenic. Also, this strain has high productivity and high conversion yield.

Keywords: Biorefinery, 1,3-propandiol, Lactobacillus reuteri, Crude glycerol, Corn steep liquor

\section{Background}

1,3-Propanediol (1,3-PDO, $\left.\mathrm{CH}_{2} \mathrm{CH}_{2}(\mathrm{OH})_{2}\right)$ is a viscous liquid that is miscible with water, and an important intermediary used for the production of polymers from

\footnotetext{
*Correspondence: kim3641@kribb.re.kr; baekrock.oh@kribb.re.kr

†Jung-Hyun Ju and Dexin Wang are co-first authors and contributed equally to this work

${ }^{1}$ Microbial Biotechnology Research Center, Jeonbuk Branch Institute, Korea Research Institute of Bioscience and Biotechnology (KRIBB), Jeongeup, Jeonbuk 56212, Republic of Korea

Full list of author information is available at the end of the article
}

petrochemical compounds. It is mainly used for production of the polyester polytrimethylene terephthalate (PTT) [1, 2], but also for the manufacture of other polymers, cosmetics, foods, lubricants, and medical products [3].

Chemical synthesis of 1,3-PDO is by the hydration of acrolein, or the hydroformylation of ethylene oxide to 3-hydroxypropionaldehyde, followed by hydrogenation [4]. The current demand for biofuels and biopolymers is driving research to increase the production efficiency and reduce costs. Biotechnology has environmental and 
economic advantages for biofuel production, because it allows use of renewable materials for the synthesis of 1,3-PDO. Some species in the bacterial genera Klebsiella [5-7], Citrobacter [8], Clostridium [9, 10], and Lactobacillus [11-13] can naturally convert glycerol into 1,3-PDO. With glycerol as a carbon source, a mutant of Klebsiella pneumoniae can produce 102.7 g/L 1,3-PDO [7] and Clostridium butyricum can produce up to $94 \mathrm{~g} / \mathrm{L}$ 1,3-PDO [10]. DuPont and Genencor International used a recombinant $E$. coli to produce up to $135 \mathrm{~g} / \mathrm{L} 1,3-\mathrm{PDO}$ from glucose [14]. However, use of these strains is problematic because of pathogenicity, the need for anaerobic growth, and the need for genetic recombination. Thus, it is imperative to select non-pathogenic, non-recombinant, and environmentally friendly strains for the commercial production of 1,3-PDO.

Lactobacillus reuteri is a hetero-fermentative bacterium that inhabits the gastrointestinal tracts of humans, pigs, birds, and other animals. This microorganism can produce 3-HPA (3-hydroxypropionaldehyde) and 1,3PDO, is "generally recognized as safe" (GRAS), non-pathogenic, and not genetically engineered. A disadvantage is that $L$. reuteri cannot grow on glycerol as the sole carbon source, so there is a need for co-fermentation (e.g., a mixture of glycerol and glucose in the culture medium) to produce 1,3-PDO. Talarico et al. [15] characterized the carbohydrate metabolism of L. reuteri. Their results showed that sugar fermentation results in the production of lactate, $\mathrm{CO}_{2}$, acetate, and ethanol when glucose is the electron acceptor. These cells, and bacterial cells generally, regenerate NADH during lactate and ethanol synthesis, and produce ATP during acetate synthesis. In addition, glycerol dehydratase (which requires a vitamin $\mathrm{B}_{12}$ cofactor) converts glycerol into 3-HPA, which is subsequently reduced by 1,3-propanediol oxidoreductase (an $\mathrm{NAD}^{+}$-dependent oxidoreductase) into 1,3-PDO. Since 1990, when Talarico et al. reported that $L$. reuteri produces small amounts of 1,3-PDO [15], other researchers have examined 1,3-PDO production in other species of Lactobacillus [11-13, 16-18]. However, all other tested Lactobacillus species only have low productivity of this compound.

Glycerol is an essential carbon source for the production of 1,3-PDO from lactic acid bacteria. Crude glycerol is a by-product of the biodiesel industry, and about $10 \%$ $(\mathrm{w} / \mathrm{w})$ glycerol is produced during biodiesel production [19]. The glycerol produced from a biodiesel plant is usually $40-70 \%(\mathrm{w} / \mathrm{w})$ before acid treatment, and $80 \%(\mathrm{w} / \mathrm{w})$ after acid treatment [20]. The amount of industrial crude glycerol production has increased as the biodiesel industry has grown. To improve the economic competitiveness of biodiesel production, it is therefore imperative to develop sustainable production of crude glycerol. This has motivated many studies to examine the production of a high-value product from crude glycerol using Lactobacillus [12, 21-23].

Nitrogen also plays an important role in microbial fermentation, and a cheap and simple organic nitrogen compound is preferable to expensive and complex nitrogen sources, such as yeast extract and beef extract [24]. Corn steep liquor (CSL), a by-product of the starch industry, is an inexpensive nitrogen source that can be used for cultivation of microorganisms, because it contains a rich complement of nitrogenous compounds, vitamins, amino acids, and biotins $[25,26]$.

The aim of the present study is to examine the effect of various operational strategies (i.e., different levels of aeration and agitation, and different nitrogen sources) on the production and productivity of 1,3-PDO using the newly isolated $L$. reuteri $\mathrm{CH} 53$. In particular, we examined 1,3PDO production using crude glycerol (a by-product of biodiesel production) and using CSL as a low-cost nitrogen source. Also, we examined the potential for further improvements in 1,3-PDO production by IC50 analysis of numerous substrates and metabolites.

\section{Methods}

\section{Chemicals and media}

Crude glycerol (80\% purity, percent weight per weight) and CSL were purchased from GS Bio (Yeosu, Korea) and Samyang Genex (Incheon, Korea), respectively. All other chemicals were of analytical grade. De Man, Rogosa, Sharpe (MRS) medium with crude glycerol was used for pre-culturing and 1,3-PDO production. Each liter of MRS medium contained $10 \mathrm{~g}$ peptone, $10 \mathrm{~g}$ beef extract, $5 \mathrm{~g}$ yeast extract, $1 \mathrm{~g}$ Tween-80, $2 \mathrm{~g} \mathrm{~K}_{2} \mathrm{HPO}_{4}, 2 \mathrm{~g}$ ammonium citrate, $5 \mathrm{~g}$ sodium acetate, $0.2 \mathrm{~g} \mathrm{MgSO}_{4}$, and $0.05 \mathrm{~g}$ $\mathrm{MnSO}_{4}$. The concentrations of glucose and crude glycerol were varied.

\section{Isolation of $L$. reuteri $\mathrm{CH} 53$}

Porcine small intestine and duodenum samples were collected from Woori Bio-Food \& Bio-Tech Co., Ltd. (Iksan, Korea). First, $1 \mathrm{~g}$ of porcine small intestine and duodenum samples were serially diluted in sterile PBS buffer (pH 6.8). Then, $100 \mu \mathrm{L}$ samples were smeared onto the surface of MRS agar (Difco, USA) containing $0.3 \mathrm{~g} / \mathrm{L}$ bromocresol purple (Sigma, USA). The Petri dishes were then incubated at $37^{\circ} \mathrm{C}$ for $24 \mathrm{~h}$ in a Bactron Anaerobic Chamber (Shellab, USA). The primary isolation was conducted using a colorimetric method using bromocresol purple. Final identification of strains was performed using the matrix-assisted laser desorption ionization (MALDI) Biotyper system (Bruker Daltonics, USA), with the modification described by Buchan et al. [27]. 
Identification of $L$. reuteri $\mathrm{CH} 53$ by $16 \mathrm{~S}$ rDNA amplification Genomic DNA was obtained using a Genomic DNA Purification Kit from Invitrogen. The 16S rRNA gene was amplified by PCR using two universal primers, 27F (5'-AGAGTTTGATCMTGGCTCAG-3') and 1492R (5'-GGTTACCTTGTTACGACTT-3'). The PCR conditions consisted of an initial denaturation step at $95{ }^{\circ} \mathrm{C}$ for $5 \mathrm{~min}$; followed by 30 cycles at $95{ }^{\circ} \mathrm{C}$ for $30 \mathrm{~s}, 55^{\circ} \mathrm{C}$ for $30 \mathrm{~s}$, and $72{ }^{\circ} \mathrm{C}$ for $90 \mathrm{~s}$; and a final step at $72{ }^{\circ} \mathrm{C}$ for $7 \mathrm{~min}$. The nucleotide sequence was determined from the amplified PCR fragment by Solutions for Generic Technologies (Solgent, Korea) and compared with available 16S rRNA gene sequences from GenBank (www.ncbi.nlm.nih.gov/ blast) and EzTaxon (eztaxon-e.ezbiocloud.net) [28]. Phylogenetic analysis was performed using MEGA6 [29] with the neighbor-joining method [30]. Bootstrap values were calculated based on 1000 replicates [31].

\section{Fermentation of $L$. reuteri $\mathrm{CH} 53$}

Seed cells for fermentation were prepared in $500 \mathrm{~mL}$ round flasks containing $300 \mathrm{~mL}$ of MRS medium with glycerol. Flasks were static-incubated at $37{ }^{\circ} \mathrm{C}$ for about $8 \mathrm{~h}$, and cultures were subsequently inoculated into growth vessels at a concentration of $10 \%(\mathrm{v} / \mathrm{v})$. Batch and fed-batch fermentations were conducted in a $5 \mathrm{~L}$ stirred-vessel system (Kobiotech. Co. Ltd., Incheon, Korea) that contained $3 \mathrm{~L}$ of MRS medium with glycerol. Unless otherwise stated, all fermentation experiments were conducted at $37{ }^{\circ} \mathrm{C}$ without aeration (only agitation, no sparging of air or $\mathrm{N}_{2}$ gas). The effect of agitation speed was determined by growing cells at 50, 100, 200, and $300 \mathrm{rpm}$. The feed to the fed-batch fermentation was using a feeding solution containing $450 \mathrm{~g}$ of glucose and $450 \mathrm{~g}$ of glycerol in $1 \mathrm{~L}$ distilled water, and the molar ratio of glucose-to-glycerol was 0.5 . The glucose and glycerol feeding began after glucose was completely consumed at a constant feed rate of $21 \mathrm{~mL} / \mathrm{h}$ (from 4 to $21 \mathrm{~h}$ ). Unless otherwise stated, the $\mathrm{pH}$ was maintained at $\mathrm{pH} 5.5 \pm 0.2$ using $28 \%(\mathrm{w} / \mathrm{v}) \mathrm{NH}_{4} \mathrm{OH}$ or $2 \mathrm{M} \mathrm{HCl}$. All presented results are averages from three independent experiments. Cell growth was monitored by removing aliquots at various times and measurement of $\mathrm{OD}_{600 \mathrm{~nm}}$ using a UV-Vis spectrophotometer (Ultrospec 3100 Pro; Amersham Biosciences, Piscataway, NJ, USA). Cells were used for enzyme activity assays, and culture broth was analyzed for metabolites.

\section{Metabolites and total nitrogen analysis}

Metabolites and glucose in the culture broth were determined using a high-performance liquid chromatography (HPLC) system (Agilent 1200) that was equipped with a refractive index detector (RID) and an Aminex HPX-87H column $(300 \times 78 \mathrm{~mm}$; Bio-Rad, Hercules, CA, USA). The mobile phase was $2.5 \mathrm{mM} \mathrm{H}_{2} \mathrm{SO}_{4}$, and the flow rate was $0.6 \mathrm{~mL} / \mathrm{min}$. The column and cell temperatures were $65{ }^{\circ} \mathrm{C}$ and $45^{\circ} \mathrm{C}$, respectively [32]. Total nitrogen concentration was measured using a HS-TN (CA)-L kit (concentration range: 1 to $50 \mathrm{mg} / \mathrm{L}$; Humas, Korea) with a HS-2300 plus water analyzer.

\section{Enzyme activity analysis}

Lactobacillus. reuteri $\mathrm{CH} 53$ cells were harvested by centrifugation and washed two times with $100 \mathrm{mM}$ phosphate buffer ( $\mathrm{pH} 7.0)$. Cells in the same buffer were disrupted using an ultrasonic system (crushing $2 \mathrm{~s}$ and rest $6 \mathrm{~s}$ for $12 \mathrm{~min}$, Power: 30\%, $210 \mathrm{~W}, 19,736 \mathrm{~Hz}$ ). A crude extract was obtained by centrifugation for $10 \mathrm{~min}$ at 13,000 rpm, and protein concentration was determined by the Bradford assay, using bovine serum albumin (BSA) as a standard. The activity of the vitamin $\mathrm{B}_{12}$-dependent glycerol dehydratase $(\mathrm{dhaB})$ was determined by measuring acrolein absorbance at $560 \mathrm{~nm}$ [33]. Because $1 \mathrm{~mol}$ of 3 -HPA is dehydrated with $1 \mathrm{~mol}$ of acrolein, the data were simply expressed as 3-HPA concentration, and $1 \mathrm{U}$ of enzyme activity was defined as the amount of enzyme required to form $1 \mathrm{mmol}$ of 3-HPA per min. The activity of 1,3-propanediol oxidoreductase (dhaT) was determined by measuring NADH absorbance at $340 \mathrm{~nm}\left(\varepsilon_{\mathrm{NADH}}=6220 \mathrm{~L} / \mathrm{mol} / \mathrm{cm}\right)$ [16], in which one unit of enzyme activity $(\mathrm{U})$ corresponds to the generation of $1 \mu \mathrm{mol}$ of NADH per min. Specific activity is expressed $\mathrm{U} / \mathrm{mg}$ protein.

\section{Measurement of IC50}

A 96-multiwell plate-based assay was used to assess the effect of each compound (glucose, glycerol, lactic acid, acetic acid, ethanol and 1,3-PDO) on 1,3-PDO production. Seed cells from an overnight culture were washed with sterile PBS ( $\mathrm{pH} 5.5)$, and then $1 \%(\mathrm{v} / \mathrm{v})$ aliquots were inoculated into an MRS-based medium containing different concentrations of the different compounds. Then $300 \mu \mathrm{L}$ of the inoculated medium was added to each well and incubated at $37{ }^{\circ} \mathrm{C}$ in a Bactron Anaerobic Chamber (Shellab, USA). To measure bacterial growth, OD was monitored at a wavelength of $600 \mathrm{~nm}$ every $2 \mathrm{~h}$ for $12 \mathrm{~h}$ using a 96-well Microplate Reader (BioTek, Korea). To calculate the IC50 for each compound, the biomass $\left(\mathrm{OD} 600_{\mathrm{nm}}\right)$ after $10 \mathrm{~h}$ was plotted against the $\log _{10}$ of the concentration.

\section{Results and discussion Isolation and identification L. reuteri $\mathrm{CH} 53$}

We identified several Lactobacillus isolates from the porcine small intestine and duodenum samples (based on their brown color on MRS agar plates), and tested 
them for growth and 1,3-PDO production in MRS medium using glycerol and glucose as co-substrates under anaerobic conditions. One isolate, $L$. reuteri $\mathrm{CH} 53$, produced abundant 1,3-PDO and grew faster than all other isolates. We investigated the identity this isolate using $16 \mathrm{~S}$ rDNA analysis. Analysis using NCBI BLAST showed it had high similarity (>99\%) to Lactobacillus reuteri JCM 1112T (AP007281). Thus, we entered the 16S rDNA sequence into the NCBI nucleotide sequence database (Accession No. MF461465) and used the neighbor-joining method to determine its relationship to other strains of Lactobacillus (Fig. 1). The results indicated that $L$. reuteri $\mathrm{CH} 53$ grouped with other strains in the genus Lactobacillus, and most closely with $L$. reuter $i$ JCM1112 (bootstrap value: $100 \%)$. This $16 \mathrm{~S}$ rRNA phylogenetic tree thus indicates that $L$. reuteri $\mathrm{CH} 53$ was in a well-supported monophyletic group that includes other Lactobacillus strains.
Effect of aeration on 1,3-PDO production in glucoseglycerol batch fermentation

We examined the effect of aeration by batch-fermentation of L. reuteri $\mathrm{CH} 53$ under aerobic condition (sparging: 1.0 volume of air per volume of liquid per min [vvm]), unaerated condition (no sparging of air), and anaerobic condition (sparging: $\mathrm{N}_{2} 1.0 \mathrm{vvm}$ ) at $200 \mathrm{rpm}$. These experiments used MRS medium with $20 \mathrm{~g} / \mathrm{L}$ glucose and $25 \mathrm{~g} / \mathrm{L}$ crude glycerol in a $5 \mathrm{~L}$ bioreactor with a $3 \mathrm{~L}$ working volume. Table 1 shows the results from these three batch-fermentation conditions at $10 \mathrm{~h}$. When the growth medium was aerated, 1,3-PDO production and cell growth were remarkably lower than under the other two conditions. The initial glycerol was almost all consumed under unaerated and anaerobic conditions, but $17.38 \pm 0.31 \mathrm{~g} / \mathrm{L}$ of the glycerol remained under aerobic conditions. Fermentation under unaerated and anaerobic conditions led

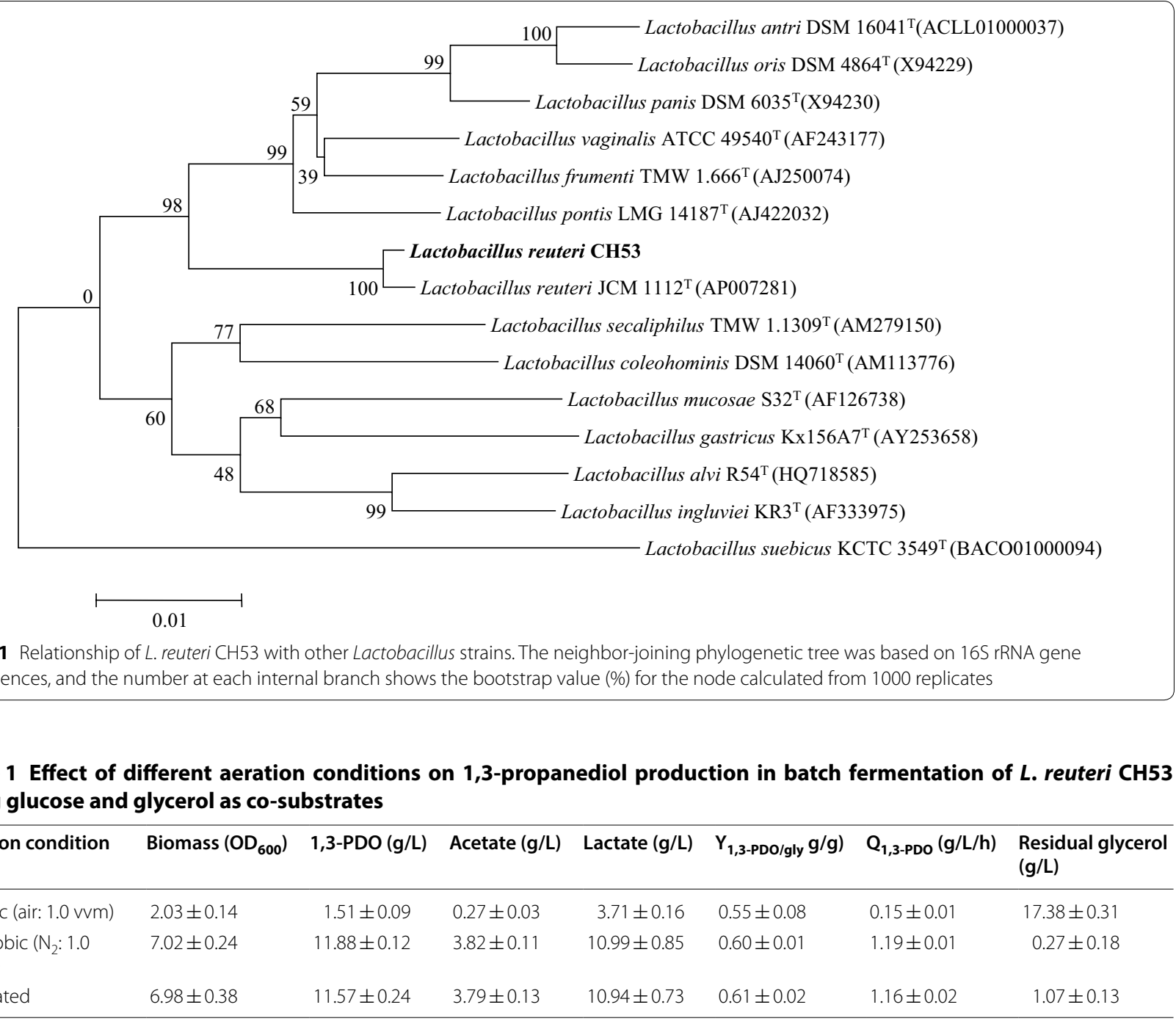

Table 1 Effect of different aeration conditions on 1,3-propanediol production in batch fermentation of $L$. reuteri CH53 using glucose and glycerol as co-substrates

\begin{tabular}{|c|c|c|c|c|c|c|c|}
\hline Aeration condition & Biomass $\left(O D_{600}\right)$ & 1,3-PDO (g/L) & Acetate $(\mathrm{g} / \mathrm{L})$ & Lactate (g/L) & $\left.\mathrm{Y}_{1,3-\mathrm{PDO} / \mathrm{gly}} \mathrm{g} / \mathrm{g}\right)$ & $\mathrm{Q}_{1,3-\mathrm{PDO}}(\mathrm{g} / \mathrm{L} / \mathrm{h})$ & $\begin{array}{l}\text { Residual glycerol } \\
\text { (g/L) }\end{array}$ \\
\hline Aerobic (air: 1.0 vvm) & $2.03 \pm 0.14$ & $1.51 \pm 0.09$ & $0.27 \pm 0.03$ & $3.71 \pm 0.16$ & $0.55 \pm 0.08$ & $0.15 \pm 0.01$ & $17.38 \pm 0.31$ \\
\hline $\begin{array}{l}\text { Anaerobic }\left(\mathrm{N}_{2}: 1.0\right. \\
\text { vvm) }\end{array}$ & $7.02 \pm 0.24$ & $11.88 \pm 0.12$ & $3.82 \pm 0.11$ & $10.99 \pm 0.85$ & $0.60 \pm 0.01$ & $1.19 \pm 0.01$ & $0.27 \pm 0.18$ \\
\hline Unaerated & $6.98 \pm 0.38$ & $11.57 \pm 0.24$ & $3.79 \pm 0.13$ & $10.94 \pm 0.73$ & $0.61 \pm 0.02$ & $1.16 \pm 0.02$ & $1.07 \pm 0.13$ \\
\hline
\end{tabular}


to production of $11.57 \pm 0.24 \mathrm{~g} / \mathrm{L}$ and $11.88 \pm 0.12 \mathrm{~g} / \mathrm{L}$ 1,3-PDO, respectively. These results thus indicate that aerobic conditions are not suitable for cell growth and 1,3 -PDO production in this strain.

Our finding of no significant differences in production of 1,3-PDO under unaerated and anaerobic conditions may be because lactic acid bacteria maintain anaerobic conditions inside the incubator due to their generation of $\mathrm{CO}_{2}$. In agreement, previous research reported that L. reuteri ATCC 55730 converted glycerol to 1,3-PDO more efficiently under unaerated and anaerobic conditions than under aerated conditions [11]. Geueke et al. [34] reported that increased oxygen promotes the activity of NADH oxidase, which regenerates $\mathrm{NAD}^{+}$and results in low production of 1,3-PDO. From an effective production point of view, unaerated conditions are also more desirable for 1,3-PDO production because many restrictions place limits on the supply of $\mathrm{N}_{2}$. Thus, we used unaerated conditions to measure $1,3-\mathrm{PDO}$ production by $L$. reuteri $\mathrm{CH} 53$ in all subsequent experiments.

\section{Effect of agitation speed on production of 1,3-PDO}

We tested the effect of agitation speed on 1,3-PDO production using $8 \mathrm{~h}$ batch-fermentation in MRS medium with $20 \mathrm{~g} / \mathrm{L}$ glucose and $25 \mathrm{~g} / \mathrm{L}$ crude glycerol without aeration (Table 2). The results indicated that cell growth decreased as agitation speed increased above $100 \mathrm{rpm}$. Maximal production $(15.58 \pm 0.56 \mathrm{~g} / \mathrm{L})$ and productivity $(1.95 \pm 0.07 \mathrm{~g} / \mathrm{L} / \mathrm{h})$ of $1,3-\mathrm{PDO}$ occurred at an agitation speed of $100 \mathrm{rpm}$. These conditions are similar to those used for cultivation of other Lactobacillus strains [17].

There are no previous reports on the effect of agitation speed on glycerol-glucose based 1,3-PDO production by other Lactobacillus strains. As the agitation speed increases, the culture broth strikes the baffle of fermentor, and this increases the surface area in contact with air, thus exposing the cells to more oxygen [35]. As reported above, we found that aerobic conditions are not suitable for cell growth and 1,3-PDO production. Thus, it is important to uniformly distribute the cells in the medium through proper agitation but without excessive splashing for efficient production of 1,3-PDO. We used an agitation speed $100 \mathrm{rpm}$ for all subsequent experiments.

Effect of fed-batch fermentation on production of 1,3-PDO Efficient fed-batch fermentation can increase the production of target bio-products [36, 37]. Thus, we tested the effect of fed-batch fermentation on 1,3-PDO production by L reuteri $\mathrm{CH} 53$ under optimized conditions (unaerated and $100 \mathrm{rpm}$ ) (Fig. 2). The molar ratios of the feeding solution for efficient fed-batch fermentation indicated the optimal molar ratio of glucose to glycerol was 0.5 (data not shown). During fed-batch fermentation, despite the presence of sufficient glucose in the culture broth, cell growth entered a stationary phase after $9 \mathrm{~h}$, which is thought to be due to the depletion of substrates essential for cell division in addition to glucose. After cell growth stopped, glucose consumption rate decreased, carbon sources accumulated in the culture medium. The concentration of glucose and glycerol in the culture broth decreased slowly after feeding stopped. The specific production rate and the specific consumption rate showed the highest result at $4 \mathrm{~h}$. The specific production rate and the specific consumption rate were decreased rapidly due to cell growth up to $9 \mathrm{~h}$. After the growth of cells ceased, the specific production rate and the specific consumption rate gradually decreased, as production rate and consumption rate decreased. Similar to the consumption of glucose, the consumption rate of glycerol was reduced and the production rate of 1,3-PDO was also reduced. $L$. reuteri strain have separate glucose and glycerol metabolic pathways, respectively [15]. The production of 1,3$\mathrm{PDO}$ is converted from glycerol, and that requires $\mathrm{NADH}$ produced by glucose metabolism. The decrease in glucose consumption rate led to a decrease in NADH production, which led to a decrease in glycerol consumption and 1,3PDO production. The maximum production of 1,3-PDO through fed-batch fermentation was $55.24 \pm 1.02 \mathrm{~g} / \mathrm{L}$ at $54 \mathrm{~h}$ and the productivity was $1.02 \pm 0.02 \mathrm{~g} / \mathrm{L} / \mathrm{h}$. The

Table 2 Effect of agitation speed on 1,3-propanediol production in batch fermentation of L. reuteri CH53 using glucose and glycerol as co-substrates

\begin{tabular}{|c|c|c|c|c|c|c|c|c|}
\hline $\begin{array}{l}\text { Agitation } \\
\text { speed } \\
\text { (rpm) }\end{array}$ & $\begin{array}{l}\text { Biomass } \\
\left(O D_{600}\right)\end{array}$ & 1,3-PDO (g/L) & Acetate (g/L) & Lactate (g/L) & $\begin{array}{l}Y_{1,3-P D O / g l y} \\
(g / g)\end{array}$ & $\mathrm{Q}_{1,3-\mathrm{PDO}}(\mathrm{g} / \mathrm{L} / \mathrm{h})$ & $\begin{array}{l}\text { Residual } \\
\text { glycerol (g/L) }\end{array}$ & $\begin{array}{l}\text { Residual } \\
\text { glucose (g/L) }\end{array}$ \\
\hline 50 & $8.40 \pm 0.26$ & $14.79 \pm 0.38$ & $7.09 \pm 0.26$ & $13.27 \pm 0.39$ & $0.73 \pm 0.02$ & $1.83 \pm 0.05$ & 0.00 & 0.00 \\
\hline 100 & $8.35 \pm 0.24$ & $15.58 \pm 0.56$ & $4.77 \pm 0.18$ & $14.18 \pm 0.38$ & $0.78 \pm 0.03$ & $1.95 \pm 0.07$ & 0.00 & 0.00 \\
\hline 200 & $6.71 \pm 0.18$ & $10.75 \pm 0.42$ & $4.10 \pm 0.16$ & $10.18 \pm 0.24$ & $0.72 \pm 0.01$ & $1.34 \pm 0.05$ & $2.02 \pm 0.48$ & $1.42 \pm 0.26$ \\
\hline 300 & $6.20 \pm 0.09$ & $7.57 \pm 0.31$ & $3.05 \pm 0.09$ & $7.73 \pm 0.22$ & $0.71 \pm 0.06$ & $0.95 \pm 0.04$ & $9.35 \pm 0.56$ & $4.02 \pm 0.35$ \\
\hline
\end{tabular}



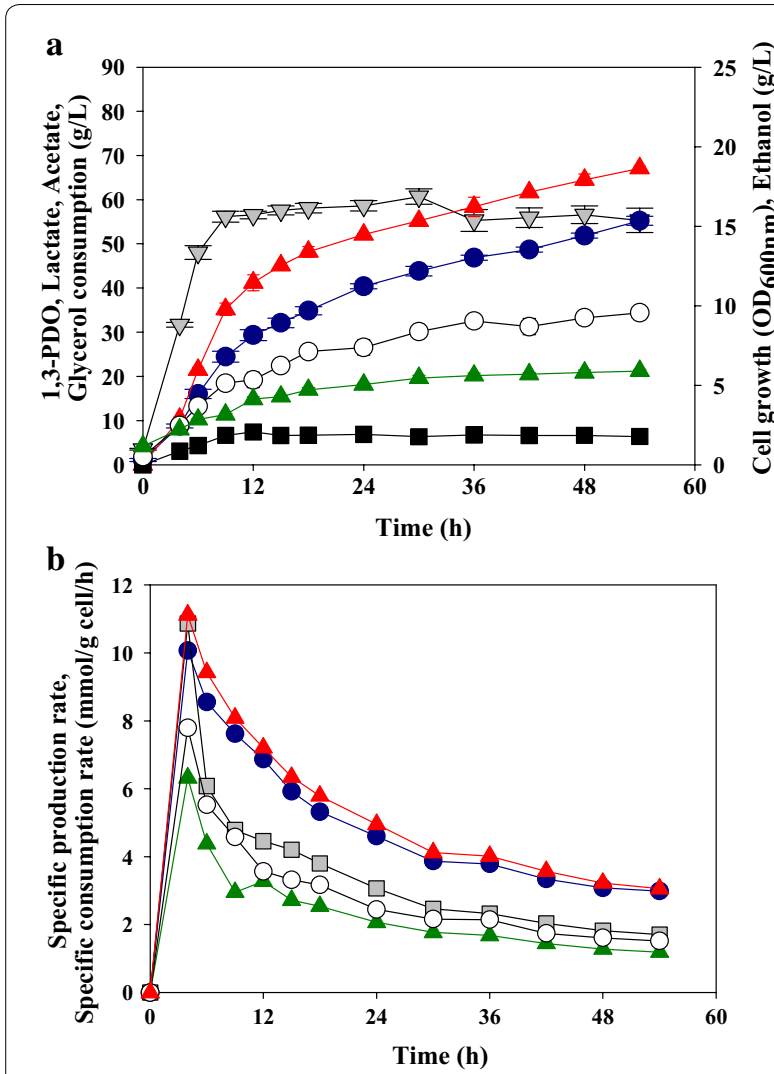

A high conversion yield is important for the economical production of 1,3-PDO in bio-refinery processes [39]. Our results thus indicate that $L$. reuteri $\mathrm{CH} 53$ has potential as an efficient 1,3-PDO producer.

\section{Effect of 1,3-PDO production using CSL as a nitrogen source}

In general, the fermentation of lactic acid bacteria is performed using MRS medium, and beef extract is the most expensive component of this medium. Thus, we tested the effect of using untreated CSL as an alternative nitrogen source on 1,3-PDO production by $L$. reuteri $\mathrm{CH} 53$. Beef extract contained $11.4 \%$ total nitrogen, and CSL contained $4.1 \%$ total nitrogen (Table 3 ), so $30 \mathrm{~g} / \mathrm{L}$ CSL used to replace $10 \mathrm{~g} / \mathrm{L}$ beef extract. The fedbatch fermentation efficiency of 1,3-PDO production improved significantly when CSL was used as a replacement (Fig. 3 and Table 4). In particular, CSL increased cell growth and led to greater production of 1,3-PDO in a shorter time than beef extract. When cells were grown for $54 \mathrm{~h}$ in fed-batch fermentation with CSL, the maximum 1,3-PDO production was $68.32 \pm 0.84 \mathrm{~g} / \mathrm{L}$ and productivity was $1.27 \pm 0.02 \mathrm{~g} / \mathrm{L} / \mathrm{h}$, the lactate production was $41.27 \pm 0.78 \mathrm{~g} / \mathrm{L}$, and the acetate production was $22.92 \pm 0.31 \mathrm{~g} / \mathrm{L}$. Thus, compared to using beef

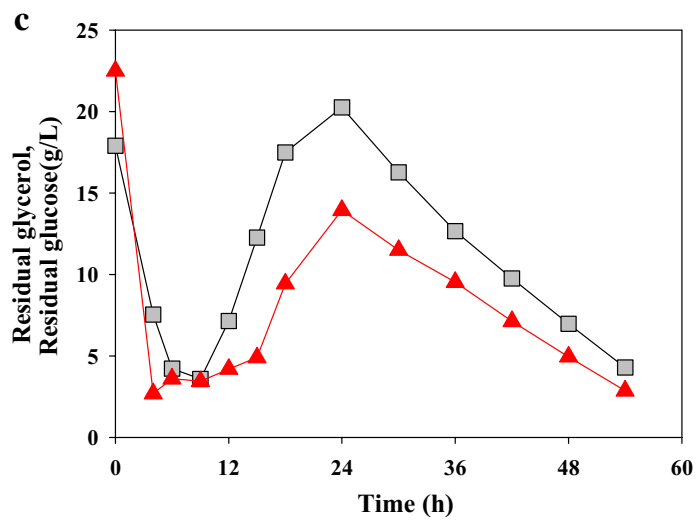

Fig. 2 Production of 1,3-propanediol and fermentation profile during fed-batch fermentation of L. reuteri CH53. a Gray down-triangles, cell growth; red up-triangles, glycerol consumption; blue circles, 1,3-propanediol; empty circles, lactic acid; green up-triangles, acetic acid; black squares, ethanol. b Gray squares, glucose; red up-triangles, glycerol; blue circles, 1,3-propanediol; empty circles, lactic acid; green up-triangles, acetic acid. c Gray squares, glucose; red up-triangles, glycerol

total amount of consumed glycerol was $67.36 \pm 0.53 \mathrm{~g} / \mathrm{L}$. The maximum theoretical conversion yield of 1,3-PDO from glycerol is $0.83 \mathrm{~g}$ 1,3-PDO per g glycerol (mol-tomol conversion) [38]. Our conversion yield was $0.82 \mathrm{~g}$ 1,3-PDO per g glycerol, $98.8 \%$ of theoretical maximum.

Table 3 Chemical characteristics of beef extract and CSL

\begin{tabular}{lll}
\hline & Beef extract & CSL \\
\hline Total nitrogen (\%) & 11.4 & 4.1 \\
Glucose (\%) & - & 0.9 \\
Lactic acid (\%) & - & 7.1 \\
$\mathrm{pH}$ & 7.3 & 4.6 \\
\hline
\end{tabular}

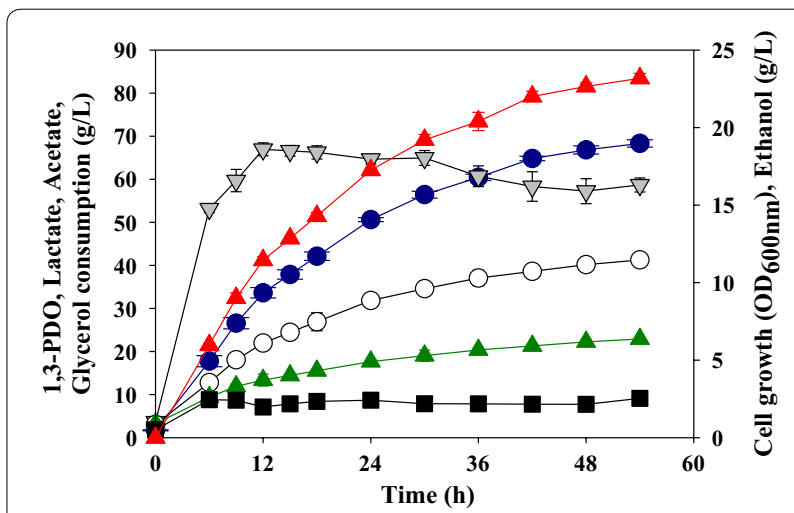

Fig. 3 Production of 1,3-propanediol and other products during fed-batch fermentation of L. reuteri CH53 using CSL as the carbon source. Gray down-triangles, cell growth; red up-triangles, glycerol consumption; blue circles, 1,3-propanediol; empty circles, lactic acid; green up-triangles, acetic acid; black squares, ethanol 
Table 4 Effect of using CSL and BE as substrates on production of 1,3-propanediol in fed-batch fermentation of $L$. reuteri CH53

\begin{tabular}{lllllll}
\hline Time $(\mathbf{h})$ & $\begin{array}{l}\text { Nitrogen } \\
\text { source }\end{array}$ & Biomass $\left(\mathbf{O D}_{\mathbf{6 0 0}}\right)$ & $\mathbf{1 , 3 - P D O}(\mathbf{g} / \mathbf{L})$ & Acetic acid (g/L) & Lactic acid (g/L) & $\mathbf{Q}_{\mathbf{1 , 3}-\mathbf{P D O}}(\mathbf{g} / \mathbf{L} / \mathbf{h})$ \\
\hline 24 & BE & $16.28 \pm 0.90$ & $40.39 \pm 0.59$ & $15.35 \pm 0.92$ & $26.54 \pm 1.06$ & $1.68 \pm 0.02$ \\
& CSL & $17.96 \pm 0.73$ & $50.63 \pm 0.77$ & $17.65 \pm 0.46$ & $31.84 \pm 0.88$ & $2.11 \pm 0.03$ \\
54 & BE & $15.36 \pm 0.76$ & $55.24 \pm 1.02$ & $21.23 \pm 0.32$ & $34.38 \pm 0.78$ & $0.99 \pm 0.02$ \\
& CSL & $15.36 \pm 0.50$ & $68.32 \pm 0.84$ & $22.92 \pm 0.31$ & $41.27 \pm 0.78$ & $1.27 \pm 0.02$ \\
\hline
\end{tabular}

$B E$ beef extract, CSL corn steep liquor

extract, use of CSL led to greater 1,3-PDO production $(68.32 \pm 0.84 \mathrm{~g} / \mathrm{L}$ vs. $55.24 \pm 1.02 \mathrm{~g} / \mathrm{L})$ and productivity $(1.27 \pm 0.02 \mathrm{~g} / \mathrm{L} / \mathrm{h}$ vs. $1.02 \pm 0.02 \mathrm{~g} / \mathrm{L} / \mathrm{h})$. The CSL used in the experiment contained $7.1 \%$ lactic acid and $0.9 \%$ glucose. However, the $30 \mathrm{~g} / \mathrm{L}$ CSL used in the fed-batch fermentation contains only $2.1 \mathrm{~g} / \mathrm{L}$ lactic acid and $0.3 \mathrm{~g} / \mathrm{L}$ glucose. There was no negative effect on fed-batch fermentation, such as inhibiting cell growth or suppressed 1,3-PDO production, because the concentration of lactic acid is very low compared to the IC50 value.

To examine the possible mechanism by which CSL improved the productivity of 1,3-PDO, we assayed enzyme activity during fed-batch fermentation (Fig. 4). The results show that cultures with $3 \%(\mathrm{w} / \mathrm{v})$ CSL had much greater $d h a B$ and $d h a T$ activity than the controls up to $48 \mathrm{~h}$. dhaB catalyzes the production of 3-HPA, a precursor of 1,3-PDO, and is a vitamin B12 dependent enzyme. It is thus possible that CSL increased $d h a B$ enzyme activity because it supplies vitamin B12 and additional nutrients not supplied by beef extract. Similarly, Pflügl et al. [17], reported vitamin B12 addition significantly enhanced the production of 1,3-PDO by Lactobacillus diolivorans and Wischral et al. [40] reported enhanced production of 1,3-PDO by Clostridium beijerinckii when CSL was used as a nitrogen source. These results suggest that CSL can be used as an effective and low-cost nitrogen source for 1,3-PDO production by L. reuteri $\mathrm{CH} 53$, and is a suitable replacement for beef extract.

\section{1,3-PDO production and productivity of other Lactobacillus strains}

Previous studies have also examined 1,3-PDO production by other Lactobacillus strains (Table 5). The highest reported production of 1,3-PDO was $92 \mathrm{~g} / \mathrm{L}$ at $165 \mathrm{~h}$ by L. diolivorans DSM 14421 [18], although the productivity from this strain was only about $0.56 \mathrm{~g} / \mathrm{L} / \mathrm{h}$. Jolly et al. [11] reported a 1,3-PDO production of $65.3 \mathrm{~g} / \mathrm{L}$ when $L$. reuteri ATCC 55730 was grown in glycerol, but the conversion yield was $0.80 \mathrm{~g} 1,3-\mathrm{PDO}$ per g glycerol, and the productivity was only $0.47 \mathrm{~g} / \mathrm{L} / \mathrm{h}$. Our strain produced 1,3-PDO of $68.32 \mathrm{~g} / \mathrm{L}$ from fed-batch fermentation at $54 \mathrm{~h}$, had a productivity of $1.27 \mathrm{~g} / \mathrm{L} / \mathrm{h}$, and had a conversion yield near the theoretical maximum of $0.83 \mathrm{~g} \mathrm{1,3-}$ PDO per g glycerol. These results indicate that $L$. reuteri $\mathrm{CH} 53$ has the highest 1,3-PDO production and productivity among tested strains of $L$. reuteri.

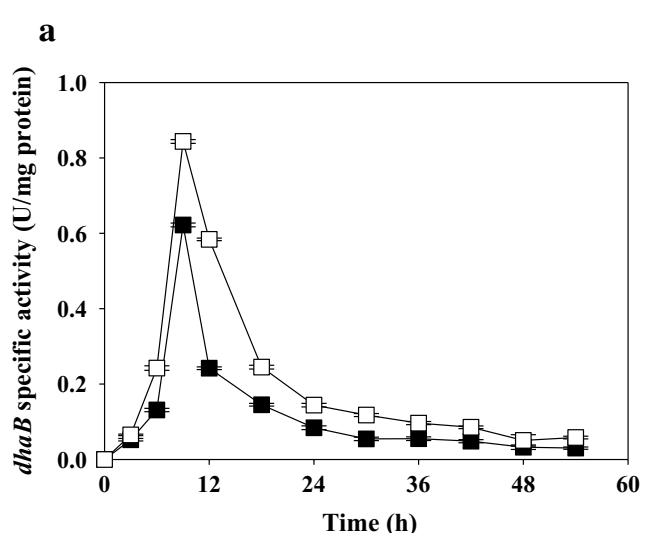

b

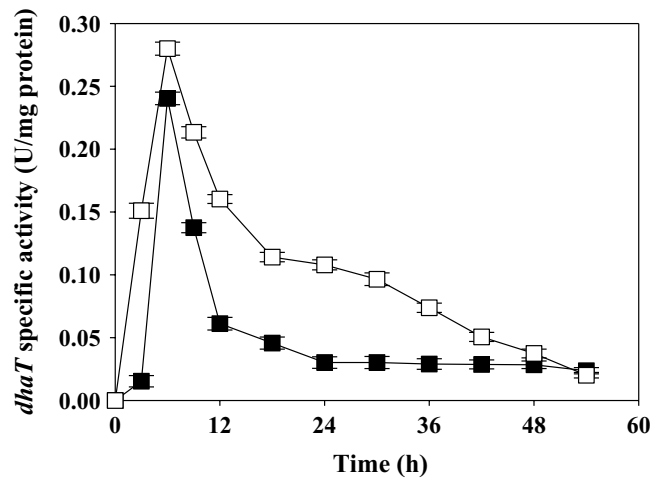

Fig. 4 Effect of CSL and beef extract on changes in enzyme activity of dhaB (a) and dhaT (b) during fed-batch fermentation of L. reuteri CH53. Closed squares, beef extract; open squares, CSL 
Table 5 Fermentation of glycerol to 1,3-PDO by different Lactobacillus strains

\begin{tabular}{llllll}
\hline Strain & $\mathbf{1 , 3 - P D O}(\mathbf{g} / \mathbf{L})$ & Yield $\mathbf{( g / g )}$ & Fermentation method & Productivity (g/L/h) & References \\
\hline L. reuteri ATCC55730 & 65 & 0.80 & Fed-batch & 0.47 & {$[11]$} \\
L. diolivorans DSM14421 & 85 & 0.53 & Fed-batch & 0.45 & {$[12]$} \\
L. reuteri DSM20016 & 46 & 0.71 & Fed-batch & 0.92 & {$[13]$} \\
L. panis PM1 & 16 & 0.72 & Batch & 0.08 & {$[16]$} \\
L. diolivorans DSM14421 & 85 & 0.47 & Fed-batch & 0.60 & {$[17]$} \\
L. diolivorans DSM14421 & 92 & 0.78 & Fed-batch & 0.56 & 1.27 \\
L. reuteri CH53 & 68 & 0.82 & Fed-batch & $18]$ & This study \\
\hline
\end{tabular}

Table 6 IC50 values of various substrates and metabolites in L. reuteri CH53

\begin{tabular}{ll}
\hline Compound & IC50 (M) \\
\hline Glucose & 1.73 \\
Glycerol & 1.52 \\
1,3-PDO & 1.05 \\
Ethanol & 0.64 \\
Lactic acid & 0.31 \\
Acetic acid & 0.29
\end{tabular}

However, L. reuteri $\mathrm{CH} 53$ performs worse than other Lactobacillus strains in terms of production concentration. We measured IC50 values to confirm the effect of different fermentation substrates and metabolites on cell growth and 1,3-PDO production (Table 6). IC50 is the concentration of agent that reduces cell growth by $50 \%$ under specified experimental conditions [13]. This allowed us to find the bottleneck of 1,3-PDO production. The IC50 values of glucose and glycerol were more than $1.5 \mathrm{M}$, so these substrates did not affect cell growth. The IC50 value of ethanol was $0.64 \mathrm{M}(29.5 \mathrm{~g} / \mathrm{L})$, but these cells produced very little ethanol during fermentation, so ethanol did not have a significant effect. The IC50 of lactic acid was $0.31 \mathrm{M}(27.9 \mathrm{~g} / \mathrm{L})$ and the IC50 of acetic acid was $0.29 \mathrm{M}(17.4 \mathrm{~g} / \mathrm{L})$. When the 1,3-PDO concentration reached $50 \mathrm{~g} / \mathrm{L}$, the productivity was $2.1 \mathrm{~g} / \mathrm{L} / \mathrm{h}$ within the first $24 \mathrm{~h}$ (Table 4), and 1,3-PDO productivity and cell growth decreased rapidly after $24 \mathrm{~h}$. At that time, the concentrations of lactic acid $(31.8 \mathrm{~g} / \mathrm{L})$ and acetic acid $(17.7 \mathrm{~g} / \mathrm{L})$ exceeded their IC50 values. Inhibition of cell growth by high lactic acid and acetic acid concentrations is caused by decreased co-factor production and enzyme activity, thus inhibiting 1,3-PDO production. In addition, the IC50 value of $1,3-\mathrm{PDO}$ was $79.9 \mathrm{~g} / \mathrm{L}$, higher than the $68.3 \mathrm{~g} / \mathrm{L}$ produced during the fed-batch fermentation. These results mean that $L$. reuteri $\mathrm{CH} 53$ can potentially produce more 1,3-PDO than described here, and that it is necessary to develop strains with enhanced resistance to lactic acid and acetic acid to further increase 1,3-PDO production. If a strain with enhanced organic acid resistance is developed using a traditional strain development methods (gamma-irradiation mutation, adaptive laboratory evolution, etc.), the advantage of using a GRAS can be maintained, and production of 1,3-PDO by $L$. reuteri $\mathrm{CH} 53$ can be competitive production.

\section{Conclusions}

Previous studies have examined the production of 1,3PDO by various lactic acid bacteria. These bacteria are useful 1,3-PDO producer because they are easy to culture and have the advantage of being GRAS. In this study, we optimized the culture of a new isolate, L. reuteri $\mathrm{CH} 53$, and improved the efficiency of 1,3-PDO production using crude glycerol and CSL as substrates. CSL was useful as an alternative nitrogen source, and it increased 1,3-PDO production by 1.24 -fold compared to MRS medium. Our results suggest that fermentation of $L$. reuteri $\mathrm{CH} 53$ using CSL as alternative nitrogen source may provide more economical and efficiently production of 1,3-PDO.

\section{Abbreviations}

L. reuteri: Lactobacillus reuteri; 1,3-PDO: 1,3-propanediol; GRAS: generally recognized as safe; GMO: genetically modified organism; 3-HPA: 3-hydroxypropionaldehyde; DhaB: coenzyme $\mathrm{B}_{12}$-dependent glycerol dehydratase; DhaT: 1,3-PDO oxidoreductase; NAD ${ }^{+}$: dependent glycerol dehydrogenase; MRS: Deman, Rogosa, Sharpe; OD $_{600 \mathrm{~nm}}$ : optical density ${ }_{600 \mathrm{~nm}}$; CSL: corn steep liquor; BE: beef extract; IC50: the half maximal inhibitory concentration.

\section{Acknowledgements}

Not applicable.

\section{Authors' contributions}

JHJ, DW and SYH contributed to design, acquisition, and analysis of data, preparation of the manuscript and carried out the experiments and analysis. MSK and JWS contributed to the revision of the project and manuscript. YMK, DHK and SAK contributed to the revision of the manuscript. CHK and BRO contributed to the concept and design of the investigation in addition to data analysis, preparation and revision of the manuscript. All authors read and approved the final manuscript.

\section{Funding}

This work was supported by the Korea Ministry of Environment as "Commercialization Project for Promising Technologies" and the KRIBB Research Initiative Program (KGM5481911). 


\section{Availability of data and materials}

The datasets supporting the conclusions of this article are included within the article.

\section{Ethics approval and consent to participate}

Not applicable.

\section{Competing interests}

The authors declare that they have no competing interests.

\section{Author details}

${ }^{1}$ Microbial Biotechnology Research Center, Jeonbuk Branch Institute, Korea Research Institute of Bioscience and Biotechnology (KRIBB), Jeongeup, Jeonbuk 56212, Republic of Korea. ${ }^{2}$ Department of Food Science \& Technology and Functional Food Research Center, Chonnam National University, Gwangju 61186, Republic of Korea. ${ }^{3}$ Radiation Utilization and Facilities Management Division, Korea Atomic Energy Research Institute, Jeongeup, Jeonbuk 56212, Republic of Korea. ${ }^{4}$ Institute for Molecular Biology and Genetics, Center for Fungal Pathogenesis, Chonbuk National University, Jeonju, Jeonbuk 54896, Republic of Korea. ${ }^{5}$ Department of Conversing Technology, Graduate School of Venture, Hoseo University, Seoul 06724, Republic of Korea.

Received: 22 September 2019 Accepted: 24 December 2019

Published online: 13 January 2020

\section{References}

1. Kaur G, Srivastava AK, Chand S. Advances in biotechnological production of 1,3-propanediol. Biochem Eng J. 2012;64:106-18.

2. Traub HL, Hirt $P$, Herlinger $H$. Mechanical properties of fibers made of polytrimethylene terephthalate. Chem Fibers Int. 1995;45:110-1.

3. Jun SA, Moon C, Kang CH, Kong S, Snag BI, Um Y. Microbial fed-batch production of 1,3-propanediol production using raw glycerol with suspended and immobilized Klebsiella pneumoniae. Appl Biochem Biotechnol. 2010;161:491-501.

4. Liu HJ, Xu YZ, Zheng ZM, Liu DH. 1,3-Propanediol and its copolymers: research, development and industrialization. Biotechnol J. 2010;5:1137-48.

5. Cheng KK, Zhang JA, Liu DH, Sun Y, Liu HJ, Yang MD, Xu JM. Pilot-scale production of 1,3-propanediol using Klebsiella pneumoniae. Process Biochem. 2007:42:740-4.

6. Huang YN, Li ZM, Shimizu K, Ye Q. Simultaneous production of 3-hydroxypropionic acid and 1,3-propanediol from glycerol by a recombinant strain of Klebsiella pneumoniae. Bioresour Technol. 2012;103:351-9.

7. Oh BR, Seo JW, Heo SY, Hong WK, Luo LH, Kim S, Park DH, Kim CH. Optimization of culture conditions for 1,3-propanediol production from glycerol using a mutant strain of Klebsiella pneumoniae. Appl Biochem Biotechnol. 2011;166:127-37.

8. Maervoet VE, De Maeseneire SL, Avci FG, Beauprez J, Soetaert WK, De Mey M. 1,3-propanediol production with Citrobacter werkmanii DSM17579: effect of a dhaD knock-out. Microb Cell Fact. 2014;13:70.

9. Kaeding T, DaLuz J, Kube J, Zeng AP. Integrated study of fermentation and downstream processing in a miniplant significantly improved the microbial 1,3-propanediol production from raw glycerol. Bioprocess Biosyst Eng. 2015;38:575-86.

10. Wilkens E, Ringel AK, Hortig D, Willke T, Vorlop KD. High-level production of 1,3-propanediol from crude glycerol by Clostridium butyricum AKR102a. Appl Microbiol Biotechnol. 2012;93:1057-63.

11. Jolly J, Hitzmann B, Ramalingam S, Ramachandran KB. Biosynthesis of 1,3-propanediol from glycerol with Lactobacillus reuteri: effect of operating variables. J Biosci Bioeng. 2014;118:188-94.

12. Pflügl S, Marx H, Mattanovich D, Sauer M. Heading for an economic industrial upgrading of crude glycerol from biodiesel production to 1,3-propanediol by Lactobacillus diolivorans. Bioresour Technol. 2014;152:499-504.

13. Ricci MA, Russo A, Pisano I, Palmieri L, de Angelis M, Agrimi G. Improved 1,3-propanediol synthesis from glycerol by the robust Lactobacillus reuteri strain DSM 20016. J Microbiol Biotechnol. 2015;25:893-902.
14. Maervoet VET, De Mey M, Beauprez J, De Maeseneire S, Soetaert WK. Enhancing the microbial conversion of glycerol to 1,3-propanediol using metabolic engineering. Org Process Res Dev. 2011;15:189-202.

15. Talarico TL, Axelsson LT, Novotny J, Fiuzat M, Dobrogosz WJ. Utilization of glycerol as a hydrogen acceptor by Lactobacillus reuteri: purification of 1,3-propanediol: NAD oxidoreductase. Appl Environ Microbiol. 1990;56:943-8.

16. Kang TS, Korber DR, Tanaka T. Glycerol and environmental factors: effects on 1,3-propanediol production and NAD+ regeneration in Lactobacillus panis PM1. J Appl Microbiol. 2013;115:1003-11.

17. Pflügl S, Marx H, Mattanovich D, Sauer M. 1,3-Propanediol production from glycerol with Lactobacillus diolivorans. Bioresour Technol. 2012;119:133-40

18. Lindlbauer KA, Marx H, Sauer M. Effect of carbon pulsing on the redox household of Lactobacillus diolivorans in order to enhance 1,3-propanediol production. N Biotechnol. 2017:34:32-9.

19. Vivek N, Sindhu R, Madhavan A, Anju AJ, Castro E, Faraco V, Pandey A, Binod P. Recent advances in the production of value added chemicals and lipids utilizing biodiesel industry generated crude glycerol as a substrate-metabolic aspects, challenges and possibilities: an overview. Bioresour Technol. 2017;239:507-17.

20. Teng WK, Ngoh GC, Yusoff R, Aroua MK. A review on the performance of glycerol carbonate production via catalytic transesterification: effects of influencing parameters. Energy Convers Manag. 2014;88:484-97.

21. Lindlbauer KA, Marx H, Sauer M. 3-Hydroxypropionaldehyde production from crude glycerol by Lactobacillus diolivorans with enhanced glycerol uptake. Biotechnol Biofuels. 2017;10:295-305.

22. Vivek N, Pandey A, Binod P. Biological valorization of pure and crude glycerol into 1,3-propanediol using a novel isolate Lactobacillus brevis N1E.9.3.3. Bioresour Technol. 2016;213:295-305.

23. Suppuram P, Ramakrishnan GG, Subramanian R. An integrated process for the production of 1,3-propanediol, lactate and 3-hydroxypropionic acid by an engineered Lactobacillus reuteri. Biosci Biotechnol Biochem. 2019;83:1-8.

24. Xia W, Chen W, Peng WF, Li KT. Industrial vitamin B12 production by Pseudomonas denitrificans using maltose syrup and corn steep liquor as the cost-effective fermentation substrates. Bioprocess Biosyst Eng. 2015:38:1065-73.

25. Khan I, Nazir K, Wang ZP, Liu GL, Chi ZM. Calcium malate overproduction by Penicillium viticola 152 using the medium containing corn steep liquor Appl Biochem Biotechnol. 2014;98:1539-46.

26. Sharma N, Prasad GS, Choudhury AR. Utilization of corn steep liquor for biosynthesis of pullulan, an important exopolysaccharide. Carbohydr Polym. 2013;93:93-101.

27. Buchan BW, Riebe KM, Ledeboer NA. Comparison of the MALDI biotyper system using sepsityper specimen processing to routine microbiological methods for identification of bacteria from positive blood culture bottles. J Clin Microbiology. 2012;50:346-52.

28. Kim OS, Cho YJ, Lee K, Yoon SH, Kim M, Na H, Park SC, Jeon YS, Lee JH, Yi H, Won S, Chun J. Introducing EzTaxon-e: a prokaryotic $16 \mathrm{~S}$ rRNA gene sequence database with phylotypes that represent uncultured species. Int J Syst Evol Microbiol. 2012;62:716-21.

29. Tamura K, Stecher G, Peterson D, Filipski A, Kumar S. MEGA6: Molecular evolutionary genetics analysis version 6.0. Mol Biol Evol. 2013;30:2725-9.

30. Saitou N, Nei M. The neighbor-joining method: a new method for reconstructing phylogenetic trees. Mol Biol Evol. 1987;4:406-25.

31. Felsenstein J. Confidence limits on phylogenies: an approach using the bootstrap. Evolution. 1985;39:783-91.

32. Oh BR, Lee SM, Heo SY, Seo JW, Kim CH. Efficient production of 1,3-propanediol from crude glycerol by repeated fed-batch fermentation strategy of a lactate and 2,3-butanediol deficient mutant of Klebsiella pneumoniae. Microb Cell Fact. 2018;17:92.

33. Raj SM, Rathnasingh C, Jo JE, Park SH. Production of 3-hydroxypropionic acid from glycerol by a novel recombinant Escherichia coli BL21 strain. Process Biochem. 2008;43:1440-6.

34. Geueke B, Riebel B, Hummel W. NADH oxidase from Lactobacillus brevis: a new catalyst for the regeneration of NAD. Enzyme Microb Technol. 2003;32:205-11.

35. Qi WK, Hojo T, Li YY. Hydraulic characteristics simulation of an innovative self-agitation anaerobic baffled reactor (SA-ABR). Bioresour Technol. 2013;136:94-101. 
36. Ju JH, Oh BR, Ryu SK, Heo SY, Kim SY, Hong WK, Kim CH, Seo JW. Production of lipid containing high levels of docosahexaenoic acid by cultivation of Aurantiochytrium sp. KRS101 using Jerusalem artichoke extract. Biotechnol Bioprocess Eng. 2018;23:726-32.

37. Ju JH, Oh BR, Ko DJ, Heo SY, Lee JJ, Kim YM, Yang KS, Seo JW, Hong WK, Kim $\mathrm{CH}$. Boosting productivity of heterotrophic microalgae by efficient control of the oxygen transfer coefficient using a microbubble sparger. Algal Res. 2019;41:101474.

38. Vieira PB, Kilikian BV, Bastos RV, Perpetuo EA, Nascimento CAO. Process strategies for enhanced production of 1,3-propanediol by Lactobacillus reuteri using glycerol as a co-substrate. Biochem Eng J. 2015;119:133-40.

39. Yang X, Kim DS, Choi HS, Kim CK, Thapa LP, Park C, Kim SW. Repeated batch production of 1,3-propanediol from biodiesel derived waste glycerol by Klebsiella pneumoniae. Chem Eng J. 2017;314:660-9.
40. Wischral D, Zhang J, Cheng C, Lim M, De Souza LMG, Pessoa FLP, Pereira N Jr, Yang ST. Production of 1,3-propanediol by Clostridium beijerinckii DSM 791 from crude glycerol and corn steep liquor: process optimization and metabolic engineering. Bioresour Technol. 2016;212:100-10.

\section{Publisher's Note}

Springer Nature remains neutral with regard to jurisdictional claims in published maps and institutional affiliations.
Ready to submit your research? Choose BMC and benefit from:

- fast, convenient online submission

- thorough peer review by experienced researchers in your field

- rapid publication on acceptance

- support for research data, including large and complex data types

- gold Open Access which fosters wider collaboration and increased citations

- maximum visibility for your research: over $100 \mathrm{M}$ website views per year

At BMC, research is always in progress.

Learn more biomedcentral.com/submissions 